\title{
Effects of sciatic-conditioned medium on neonatal rat retinal cells in vitro
}

P.M.M. Torres ${ }^{1,2}$,

C.V.V. Guilarducci ${ }^{1}$ and E.G. Araujo ${ }^{1}$

\author{
1Departamento de Neurobiologia, Instituto de Biologia, \\ Universidade Federal Fluminense, Niterói, RJ, Brasil \\ 'Instituto de Biofísica Carlos Chagas Filho, Centro de Ciências da Saúde, \\ Universidade Federal do Rio de Janeiro, Rio de Janeiro, RJ, Brasil
}

\author{
Correspondence \\ P.M.M. Torres \\ Departamento de Neurobiologia \\ Instituto de Biologia, UFF \\ Caixa Postal 100180 \\ 24001-970 Niterói, RJ \\ Brasil \\ Fax: + 55-21-719-5934 \\ E-mail: adrianno@ openlink.com.br \\ Research supported by CAPES, \\ CEG-UFF, FAPERJ and FINEP. \\ P.M.M. Torres was the recipient \\ of a CAPES fellowship.
}

Received April 30, 1998

Accepted August 13, 1998

\section{Abstract}

Schwann cells produce and release trophic factors that induce the regeneration and survival of neurons following lesions in the peripheral nerves. In the present study we examined the in vitro ability of developing rat retinal cells to respond to factors released from fragments of sciatic nerve. Treatment of neonatal rat retinal cells with sciatic-conditioned medium (SCM) for $48 \mathrm{~h}$ induced an increase of $92.5 \pm 8.8 \%(\mathrm{~N}=7$ for each group) in the amount of total protein. SCM increased cell adhesion, neuronal survival and glial cell proliferation as evaluated by morphological criteria. This effect was completely blocked by $2.5 \mu \mathrm{M}$ chelerythrine chloride, an inhibitor of protein kinase $\mathrm{C}$ (PKC). These data indicate that PKC activation is involved in the effect of SCM on retinal cells and demonstrate that fragments of sciatic nerve release trophic factors having a remarkable effect on neonatal rat retinal cells in culture.

Neuronal differentiation and survival are supported by several microenvironmental signals in the nervous system (1) throughout its development as well as in its adult phase (2). Some of these signalling molecules are generally named cytokines and include interleukins, growth factors, differentiation factors and neurotrophic factors (3). These molecules are produced by target cells, afferent cells, glial cells and also by neurons themselves in an autocrine mechanism (4). There is much evidence that cytokines increase the survival of neurons, promote neurite extension and induce phenotypic changes $(2,3)$.

After lesion, Schwann cells, the glial elements of the peripheral nervous system (PNS), produce and release several cytokines including nerve growth factor (NGF), brain-derived neurotrophic factor (BDNF), neurotrophin-3 (NT-3), ciliary neurotrophic factor (CNTF), interleukin-6 (IL-6), tumor necrosis factor alpha (TNF $\alpha)$, and leukemia inhibitory factor (LIF) (5-10). In this context these cytokines are usually named lesion factors $(5,6)$. The ability of Schwann cells to promote experimentally remyelination and regeneration in central axons is of particular interest. Accordingly, these cells have a remarkable potential for inducing regeneration throughout the nervous system.

To study the action of factors released by a peripheral nerve on developing central neurons, we analyzed the effect of sciatic-conditioned medium (SCM) on neonatal rat retinal cells. SCM increased survival and cell adhesion of retinal cells in vitro. Our data suggest 
Figure 1 - Phase contrast photomicrographs of retinal cells kept in culture for $48 \mathrm{~h}$. Control cultures $(\mathrm{A})$ and cultures treated with sciatic-conditioned medium 1:1 (B). The plating density was $1.0 \times 10^{5}$ cells $/ \mathrm{cm}^{2}$. Note the presence of large clusters (asterisk) of neuronal cells (arrow) over glial cells (arrowhead) in the cultures. Magnification bar: 50 $\mu \mathrm{m}$. that lesion factors released by fragments of sciatic nerve have a remarkable effect on neonatal rat retinal cells in culture.

Primary cultures were prepared using procedures previously described (11). Briefly, Lister Hooded neonatal rats at postnatal day 1 (P1) were killed by decapitation and their retinas dissected free from scleral tissue and pigmented epithelium in a calcium- and magnesium-free balanced salt solution (CMF). The retinas were incubated in CMF containing $0.1 \%$ trypsin (Worthington, Freehold, $\mathrm{NJ}, \mathrm{USA}$ ) for approximately $16 \mathrm{~min}$ at $37^{\circ} \mathrm{C}$. The cells were mechanically dissociated using a polished Pasteur pipette and added to plastic Petri dishes $(35 \mathrm{~mm})$ at a plating density of $1.0 \times 10^{5}$ cells $/ \mathrm{cm}^{2}$ in complete culture medium (199; Gibco, Gaithersburg, MD, USA) containing $2 \mathrm{mM}$ glutamine, 100 $\mu \mathrm{g} / \mathrm{ml}$ streptomycin $+100 \mathrm{U} / \mathrm{ml}$ penicillin (Sigma Chemical Co., St. Louis, MO, USA) and $5 \%$ fetal calf serum. The SCM was obtained from adult Lister Hooded rats using a method developed in our laboratory. The rats were killed by ether asphyxia and segments of the sciatic nerves (approximately 2 $\mathrm{cm}$ ) were dissected in CMF solution con-
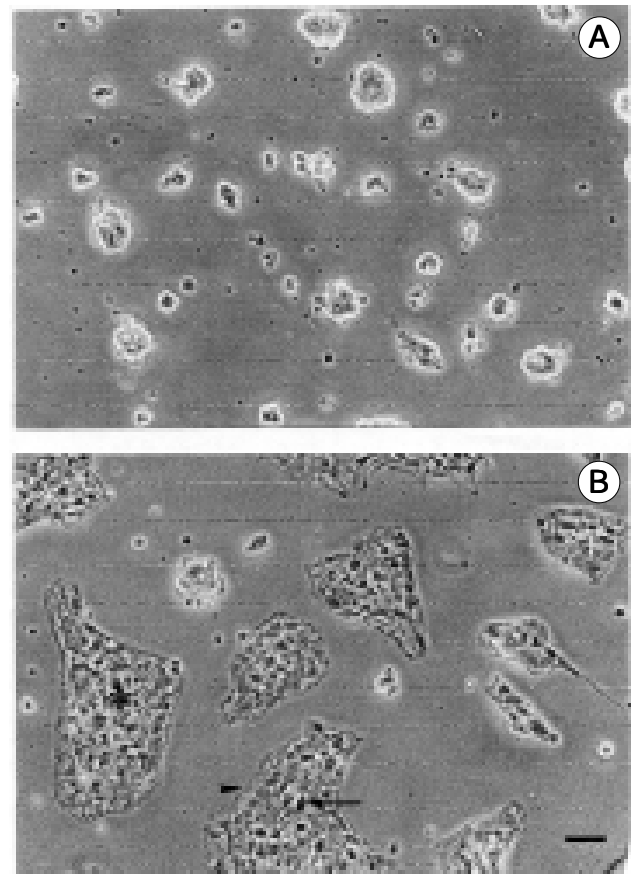

taining $200 \mu \mathrm{g} / \mathrm{ml}$ streptomycin $+200 \mathrm{U} / \mathrm{ml}$ penicillin. The nerves were minced into fragments of $2 \mathrm{~mm}$ and incubated in a $35-\mathrm{mm}$ Petri dish with complete culture medium (2 $\mathrm{ml})$ at $37^{\circ} \mathrm{C}$ in an atmosphere of $5 \% \mathrm{CO}_{2} /$ 95\% air. The medium was changed completely twice a week. The supernatant thus obtained after 14 days in vitro was sterilized by filtration through a membrane of $0.2 \mu \mathrm{m}$ and kept at $4^{\circ} \mathrm{C}$. To test the effect of SCM, the supernatant was diluted 1:1 in complete culture medium. Retinal cells received complete culture medium or SCM and/or $2.5 \mu \mathrm{M}$ chelerythrine chloride immediately after plating and were kept in vitro for $48 \mathrm{~h}$ at $37^{\circ} \mathrm{C}$ in an atmosphere of $5 \% \mathrm{CO}_{2} / 95 \%$ air. The morphological changes induced by SCM were visualized by light microscopy and the total amount of protein was quantified by the method of Lowry et al. (12).

It was easy to observe that SCM induced an increase in retinal cell adhesion, neuronal survival and glial cell proliferation. When retinal cells were plated onto tissue culture dishes without previous treatment with polyL-ornithine they formed very small cell clusters (Figure 1A). However, when SCM was added to the cultures, the size of each individual cluster was significantly increased (Figure 1B). Each cluster comprised glial cells firmly attached to the Petri dish and neuronal cells lying on the top of glial cells (Figure 1B).

In order to quantify the effect of SCM we used the method of Lowry to compare the total amount of protein in control cultures with cultures treated with SCM. SCM induced an increase of $92.5 \pm 8.81 \%(\mathrm{~N}=7)$ in the amount of protein when compared with control cultures (Figure 2). This result corresponds to morphological alterations described in Figure 1A,B.

To determine if the effect of SCM was mediated by protein kinase $\mathrm{C}$ (PKC), we studied the effect of a specific inhibitor of this enzyme in cultures treated with SCM. The results showed that $2.5 \mu \mathrm{M}$ chelerythrine 
chloride inhibited $80 \%$ of the SCM effect (Figure 2). However, the treatment with 2.5 $\mu \mathrm{M}$ chelerythrine chloride alone did not decrease the total amount of protein when compared with control cultures, indicating that the reduction of the SCM effect was not due to the toxicity of the drug (Figure 2).

The purpose of this study was to investigate the effect of factors released by adult peripheral nerves on developing central nervous system cells (CNS) in vitro. Schwann cells are the predominant cell type in the sciatic nerve (13) and our in vitro data suggest that the effect of SCM could be due to cytokines released by Schwann cells following incubation of sciatic fragments in vitro. Schwann cells are the cellular component for successful PNS regeneration (13) and in a CNS model in which regeneration cannot proceed, these cells are essential elements for the support of central axon regrowth (5).

Our results indicate that Schwann cells present in sciatic nerve fragments synthesize and secrete factors that support survival, cell adhesion and glial cell proliferation of retinal cells in culture. Laminin is known to be synthesized by Schwann cells in vitro (14) and SCM could contain this or other substratum-binding matrix proteins that promote neuritic outgrowth and cell adhesion. However, preliminary results indicate that preadsorption of SCM does not mimic the effect produced by SCM on retinal cells.

Initially the cells respond to extracellular stimuli through a series of signal transductions across the cell membrane. Many of the proteins mediating this process have been identified as PKC-like enzymes. PKC con-

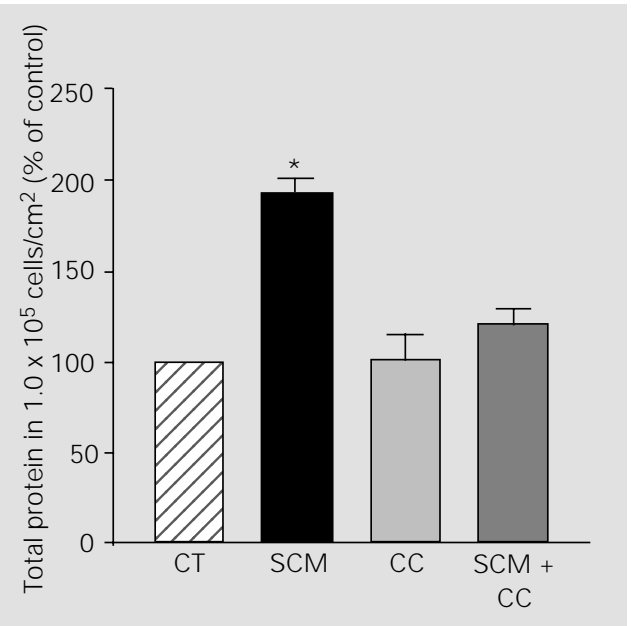

stitutes a structurally homologous family of enzymes that are activated by cell membrane lipids and that catalyze the rapid and reversible phosphorylation of serine or threonine residues in a wide variety of proteins. By this mechanism, PKC modulates the biological functions of these proteins, controlling diverse processes including growth, differentiation, neural development, synaptic transmission and axonal regeneration (15). The inhibition of the effect of SCM on the retinal cells in culture by $2.5 \mu \mathrm{M}$ chelerythrine chloride suggests that a PKC transduction pathway is involved. However, a complete understanding of the mechanisms by which SCM activates this PKC pathway in retinal cells is not available.

\section{Acknowledgments}

We acknowledge the technical assistance of Alexandre José Fernandes and Bernardino Matheus dos Santos.
Figure 2 - Effect of sciatic-conditioned medium on the protein content of retinal cultures. The cells were incubated for $48 \mathrm{~h}$ with control medium (CT), sciatic-conditioned medium (SCM) $1: 1,2.5 \mu \mathrm{M}$ chelerythrine chloride $(\mathrm{CC})$ or SCM + CC. The plating density was $1.0 \times 10^{5}$ cell/ $\mathrm{cm}^{2}$. Data are reported as the mean \pm SEM, percent of control, for 4 independent experiments, each performed in duplicate. $* \mathrm{P}<0.001$ compared to the 48-h control (ANOVA followed by the Newman-Keuls test). The protein content of control cultures was $\cong 50 \mu \mathrm{g} /$ Petri dish. 


\section{References}

1. Burek MJ \& Oppenheim RW (1996). Programmed cell death in the developing nervous system. Brain Pathology, 6: 427-446.

2. Svendsen CN \& Sofroniew MV (1996). Do central nervous system neurons require target-derived neurotrophic support for survival throughout adult life and aging? Perspectives on Developmental Neurobiology, 3: 133-142.

3. Korsching S (1993). The neurotrophic factor concept: a reexamination. J ournal of Neuroscience, 13: 2739-2748.

4. Lo AC, Houenou LJ \& Oppenheim RW (1995). Apoptosis in the nervous system: morphological features, methods, pathology, and prevention. Archives of Histology and Cytology, 58: 139-149.

5. Bunge RP (1994). The role of the Schwann cell in trophic support and regeneration. J ournal of Neurology, 241: S19-S21.

6. Thoenen $\mathrm{H}$ (1991). The changing scene of neurotrophic factors. Trends in Neurosci- ences, 14: 165-170.

7. Bolin LM, Verity AN, Silver J E, Shooter EM \& Abrams J S (1995). Interleukin-6 production by Schwann cells and induction in sciatic nerve injury. J ournal of Neurochemistry, 64: 850-858.

8. Sendtner $M$, Sotöckli KA \& Thoenen $H$ (1992). Synthesis and localization of ciliary neurotrophic factor in the sciatic nerve of the adult rat after lesion and during regeneration. J ournal of Cell Biology, 118: 139-148.

9. Wagner R \& Myers RR (1996). Schwann cells produce tumor necrosis factor alpha: expression in injured and non-injured nerves. Neuroscience, 73: 625-629.

10. Kurek J B, Austin L, Cheema SS, Bartlett PF \& Murphy M (1996). Up-regulation of leukaemia inhibitory factor and interleukin- 6 in transected sciatic nerve and muscle following denervation. Neuromuscular Disorders, 6: 105-114.
11. Araujo EG \& Linden R (1993). Trophic factors produced by retinal cells increase the survival of retinal ganglion cells in vitro. European J ournal of Neuroscience, 5: 1181-1188.

12. Lowry $\mathrm{OH}$, Rosenbrough NJ , Farr AL \& Randall RJ (1951). Protein measurement with the Folin phenol reagent. J ournal of Biological Chemistry, 193: 265-275.

13. Zorick TS \& Lemke G (1996). Schwann cell differentiation. Current Opinion in Cell Biology, 8: 870-876.

14. Combrooks CJ , Carey DJ , McDonald J A, Timple R \& Bunge RP (1983). In vivo and in vitro observation on laminin production by Schwann cells. Proceedings of the $\mathrm{Na}$ tional Academy of Sciences, USA, 80: 3850-3854.

15. Singer HA (1996). Protein kinase C. In: Biochemistry of Smooth Muscle Contraction. Academic Press, New York. 